\title{
Attribution of typhoon-induced torrential precipitation in Central Vietnam, October 2020
}

\author{
Linh N. Luu ${ }^{1,2} \cdot$ Paolo Scussolini ${ }^{1,3} \cdot$ Sarah Kew ${ }^{1} \cdot$ Sjoukje Philip ${ }^{1}$. \\ Mugni Hadi Hariadi ${ }^{1} \cdot$ Robert Vautard $^{4} \cdot$ Khiem Van Mai $^{5} \cdot$ Thang Van $\mathrm{Vu}^{2}$. \\ Kien Ba Truong ${ }^{2} \cdot$ Friederike Otto $^{6}$. Gerard van der Schrier ${ }^{1}$. \\ Maarten K. van Aalst ${ }^{7,8,9}$. Geert Jan van Oldenborgh ${ }^{1}$
}

Received: 26 April 2021 / Accepted: 28 October 2021/Published online: 14 December 2021

(C) The Author(s) 2021

\begin{abstract}
In October 2020, Central Vietnam was struck by heavy rain resulting from a sequence of 5 tropical depressions and typhoons. The immense amount of water led to extensive flooding and landslides that killed more than 200 people, injured more than 500 people, and caused direct damages valued at approximately 1.2 billion USD. Here, we quantify how the intensity of the precipitation leading to such exceptional impacts is attributable to anthropogenic climate change. First, we define the event as the regional maximum of annual maximum 15-day average rainfall (Rx15day). We then analyse the trend in Rx15day over Central Vietnam from the observations and simulations in the PRIMAVERA and CORDEX-CORE ensembles, which pass our evaluation tests, by applying the generalised extreme value (GEV) distribution in which location and scale parameters exponentially covary with increasing global temperatures. Combining these observations and model results, we find that the 2020 event, occurring about once every 80 years (at least 17 years), has not changed in either probability of occurrence (a factor 1.0, ranging from 0.4 to 2.4) or intensity $(0 \%$, ranging from -8 to $+8 \%)$ in the present climate in comparison with earlyindustrial climate. This implies that the effect of human-induced climate change contributing to this persistent extreme rainfall event is small compared to natural variability. However, given the scale of damage of this hazard, our results underline that more investment in disaster risk reduction for this type of rainfall-induced flood hazard is of importance, even independent of the effect of anthropogenic climate change. Moreover, as both observations and model simulations will be extended with the passage of time, we encourage more climate change impact investigations on the extreme in the future that help adaptation and mitigation plans and raise awareness in the country.
\end{abstract}

Keywords Heavy rainfall $\cdot$ Attribution $\cdot$ Typhoon $\cdot$ Climate change $\cdot$ Extreme events

This article is part of the topical collection "Weather Attribution".

Linh N. Luu

linh.luu@knmi.nl

Extended author information available on the last page of the article 


\section{Introduction}

\subsection{Characterisation of the cyclonic events of October 2020}

In October 2020, Vietnam was greatly affected by several persistent heavy precipitation events occurring sequentially during the month. Resulting from a series of cyclones, including two tropical depressions and three typhoons, in conjunction with cold surges moving southward from mainland China, these devastating events hit the coast of Central Vietnam, specifically the North Central and South Central climatic subregions (see Fig. 1a). The first event started on 6 October when a low pressure system made landfall along the south central coast (Fig. 2a). Massive quantities of moisture brought by the easterly winds were uplifted upon meeting the high topography of the Truongson mountain range, which lies along the boundary between Vietnam and Laos (Fig. 1a), leading to heavy rainfall lasting until 9 October. The orographic lift shown in Fig. 2a indicates that strong convection took place on the windward side of the Truongson mountain range, while downdraft dominated on the leeward side. Subsequently, typhoon Linfa struck the coast of Vietnam on 11 October around $16^{\circ} \mathrm{N}$ (Fig. 2b). This typhoon produced heavy rainfall along its westward path over Vietnam until the $13^{\text {th }}$ of October. During this event, a few stations observed rainfall in excess of $550 \mathrm{~mm}$ in a day, with a peak of $629 \mathrm{~mm} /$ day at the Namdong station on 10 October (Fig. 1b).

On 16 October, another tropical depression, dubbed Ofel by the Philippine Atmospheric, Geophysical and Astronomical Services Administration, brought large quantities of rain to the central region of Vietnam, stalling over the coast of this area on 17 and 18 October before downgrading and disappearing the next day. However, the moist easterly flow, in association with the cold surge from the north, lingered on, impinging on the mountainous terrain of this area until 20 October (Fig. 2) and contributing several waves of heavy rainfall onto the mainland. Heavy precipitation was recorded at all stations within the two climatic subregions. An amount exceeding $500 \mathrm{~mm} /$ day was witnessed at a few stations, and an amount exceeding $1000 \mathrm{~mm}$ in 2 days was observed at Hatinh station. The daily peak of this event was $756 \mathrm{~mm} /$ day recorded at the Badon station on the $19^{\text {th }}$ of October (Fig. 1b) that was even more intense than the heavy precipitation caused by Linfa.

The last extreme precipitation events of the series resulted from two consecutive typhoons in the last week of October. Typhoon Saudel made landfall around $16^{\circ} \mathrm{N}$ to $17^{\circ} \mathrm{N}$ on 25 October. Its convection in association with the Truongson mountain range was less strong than during the previous events (Fig. 2e), bringing less precipitation with a peak of $94 \mathrm{~mm} /$ day at the Conco station on 25 October (Fig. 1b). On 28 October, typhoon Molave hit Vietnam's coast (Fig. 2f), initiating intense rainfall over a large area from $13^{\circ} \mathrm{N}$ to $20^{\circ} \mathrm{N}$ (Fig. 1b) over the remainder of the month. The whole set of events brought accumulated rainfall ranging from $140 \mathrm{~mm}$ to more than $3500 \mathrm{~mm}$ in a month with devastating impacts on the population of this area. In fact, heavy rainfall kept striking Central Vietnam in the first half of November as a consequence of three typhoons Goni, Etau, and Vamco hitting the coast. However, we would focus only on the series of heavy rainfall events in October in this study. 

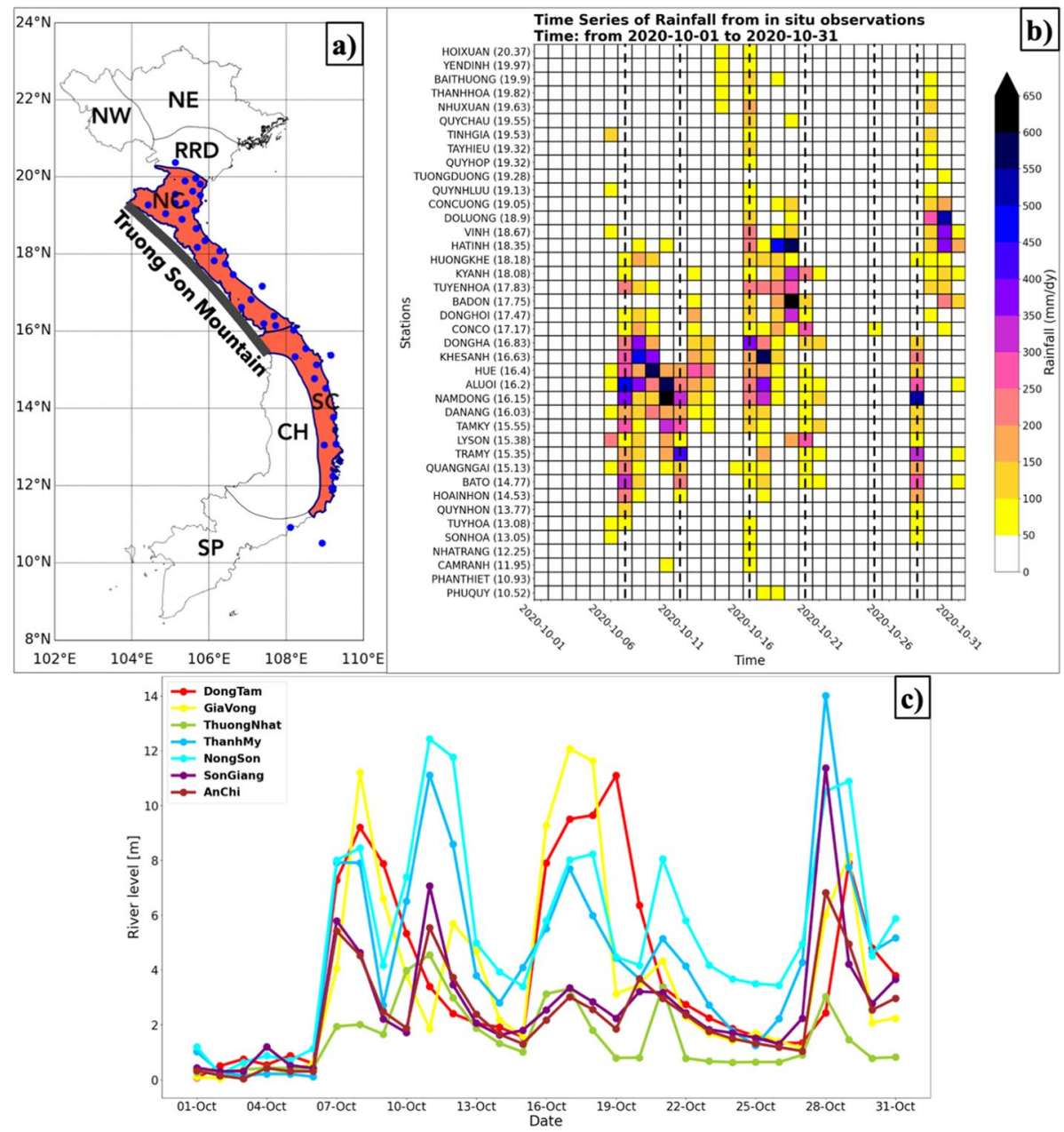

Fig. 1 a The seven climatic subregions of Vietnam (Nguyen and Nguyen 2004) including Northwest (NW), Northeast (NE), Red River Delta (RRD), North Central (NC), South Central (SC), Central Highland (CH), and Southern Plain (SP). The two subregions analysed in this study are NC and SC, shaded in red. The blue dots denote meteorological stations used in this study; $\mathbf{b}$ time series of daily rainfall over stations in Central Vietnam for October 2020. The stations are sorted in descending order of latitude, which is given within the brackets next to the station's name. The vertical dashed lines mark the dates whose large-scale patterns are analysed in Fig. 2. c Daily maxima of river level at seven hydrological stations (around the $16^{\circ} \mathrm{N}$ ) in Central Vietnam relative to their lowest recorded in October 2020.

\subsection{Impact of the torrential rains}

The torrential precipitation events in association with steep topography of the Truongson range in Central Vietnam led to a series of long lasting large-scale floods and landslides during the month. Fig. 1c shows river levels at eight hydrological stations in Central Vietnam as the difference with their lowest observed in October 2020. One sees persistent floods of up to $10 \mathrm{~m}$ above the lowest level of the month around the $20^{\text {th }}$ of October, with a more separate peak on the $29^{\text {th }}$. According to the Vietnam Disaster 


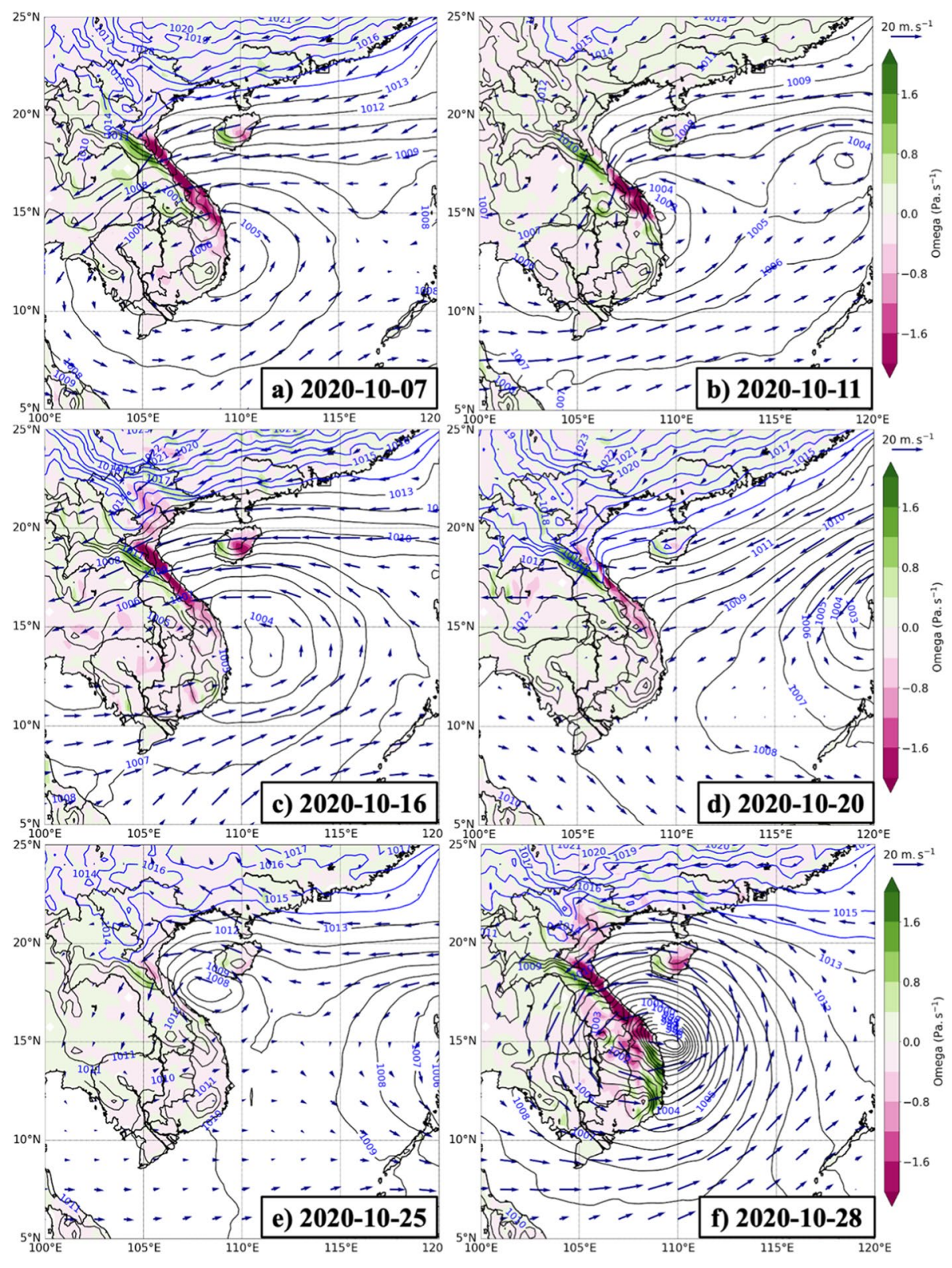

Fig. 2 a to $\mathbf{f}$ Large-scale patterns for the selected dates when tropical cyclones hit the Vietnam coast. Shown are mean sea level pressure (MSLP), in contoured lines (blue contour lines are MSLP greater than $1013 \mathrm{mb}$ that depicts effect of cold surge from Tibetan high pressure system), and wind vectors $\left(\mathrm{m} . \mathrm{s}^{-1}\right.$ ) and vertical wind velocity (Pa.s ${ }^{-1}$, shaded) all at $850 \mathrm{mb}$ level. Data are from the ERA5 reanalysis (Hersbach et al. 2020).

Management Authority (VDMA), the events from 6 to 20 October killed 138 people, with 16 people reported missing and 398 wounded. The events damaged more than 6200 homes beyond repair and submerged more than 375,000 houses. Flooding and 
landslides also devastated $167 \mathrm{~km}^{2}$ of crops, swept away 105 thousand tons of food, and killed approximately 2.6 million of cattle and poultry. Several hundred kilometres of canals, dams, and roads were eroded and damaged. As it was characterised by a much lower precipitation rate, typhoon Molave brought losses and damages smaller than the previous two events, including 83 fatalities and missing people, 140 wounded, 190 thousand damaged houses and 31 thousand submerged houses, $21 \mathrm{~km}^{2}$ of crop ruined, and 680 thousand cattle and poultry killed. A few hundreds of kilometres of roads and infrastructure were destroyed. The initial estimate of losses and damages in the aftermath of all events in October was 1.2 billion US dollars (all numbers are from VDMA).

\subsection{Extreme weather of Central Vietnam}

Vietnam is located at the intersection of several regional large-scale weather systems: the summer Asian monsoon, the winter Asian monsoon, and the migration of the Intertropical Convergence Zone (ITCZ). Moreover, Vietnam is prone to on average 6 tropical cyclones landfalling every year within a latitudinal corridor roughly from $8^{\circ} \mathrm{N}$ to $23^{\circ} \mathrm{N}$, corresponding to $3260 \mathrm{~km}$ of coastline (Pham et al. 2018; Takagi 2019). Rainfall patterns over the country are substantially governed by the combination of these regional systems (Tuan 2019; Wolf et al. 2020). In addition, the El Niño-Southern Oscillation (ENSO) strongly affects heavy precipitation variability in Vietnam, with cold ENSO stage, i.e. La Nina, typically intensifying precipitation and inducing flooding (Chen et al. n.d.; Yen et al. 2011; Van Vu et al. 2015; Gobin et al. 2016). Another factor that can lead to unusual extreme rainfall events in Vietnam is the strong active eastward phase of the Madden Julian Oscillation coinciding with the westward propagation of tropical disturbances and winter monsoon (Wu et al. 2012). The peak in the rainy season over Central Vietnam occurs in late autumn and early winter when the north-easterly winter monsoon appears and coincides with tropical cyclones and disturbances favoured by the ITCZ. Spatially, high rainfall is associated with high and steep topography of the Truongson mountain range (Yokoi and Matsumoto 2008; Tuan 2019). Especially, when a cold surge from the north (i.e. the winter monsoon) dominates over Central Vietnam and lingers for a couple of days to a week, and/ or one or more tropical cyclones/cyclonic circulations affects the area in a short period of time, persistent heavy orographic rainfall occurs in this area (NCHMF 2000; Yokoi and Matsumoto 2008; Chen et al. 2012). The catastrophic rainfall event that we address in this study is a typical example of the combined effect of cold surge, cyclonic circulations, and orographic lifting.

\subsection{Motivation for the attribution of the October 2020 events}

Vietnam is one of the most hazard-vulnerable countries in the world (Brown 2009). In recent years, many flood-generating tropical cyclones and other heavy precipitation events were observed over this area. Villafuerte and Matsumoto (2015) found that observed extreme daily rainfall has increased over Central Vietnam and that this trend covaries with global mean temperature. This raises questions about a potential role of climate change in changing patterns of rainfall extremes (Villafuerte and Matsumoto 2015). Additionally, tropical cyclones affecting Vietnam are projected to increase in both intensity and frequency under future warming climate scenarios (Wang et al. 2017; Torres-Alavez et al. 2021b). Supari and Juneng (2020) project extreme daily rainfall to increase by the end of this century under both Representative Concentration Pathway scenarios RCP4.5 and 
RCP8.5. Despite these indications of the emergence of a concerning trend, there has been no formal attribution study that investigates the role of climate change on any extreme event relating to flooding in this country. In this study, we quantify the impact of anthropogenic climate change on the heavy precipitation event in October 2020 in Central Vietnam, which resulted in extremely large losses and damages due to floods and landslides enhanced by the topography, state of infrastructure, and exposure and vulnerability of people and assets.

In recent years, there has been a strong increase in studies investigating the connections between extreme events and climate change in the aftermath of specific extreme eventsalso called extreme event attribution (EEA). There are theoretical arguments that suggest that daily rainfall extremes would scale with the amount of moisture available in the atmosphere. For a constant relative humidity, this is proportional to the Clausius-Clapeyron (CC) relation for saturation humidity, which increases by about $7 \%$ per degree, although it is not clear where the increase in temperature should be evaluated, at the moisture source or where the precipitation falls. In practice, many regions also deviate from this due to other influences. For example, Eden et al. (2016) showed that increases in 1-day precipitation extremes in Boulder, Colorado, are much smaller than CC scaling, whereas Van Oldenborgh et al. (2017) showed that the 3-day heavy precipitation event that resulted from Hurricane Harvey over Houston, Texas, was double of CC scaling (15\%, from 8 to 19\%) by anthropogenic climate change. This corresponds to an event of at least the intensity of Harvey being 3 (1.5 to 5) times more likely under a warming world. van der Wiel et al. (2017) showed that the 3-day heavy precipitation event in south Louisiana in August 2016 was at least 1.4 times more likely under anthropogenic climate change. The impact of climate change on the heavy precipitation event in late May/early June 2016 in France was also estimated to lead to an increase in probability of heavy precipitation by a factor of at least 1.4 (Philip et al. 2017). However, the effect of human-induced climate change was occasionally not found in different areas in the world, e.g. heavy rainfall in December 2015 in Chennai, India (van Oldenborgh et al. 2016), wet season 2015 in Nigeria (Lawal et al. 2016), wet winter 2016 in Southeast Australia, extreme rainfall in winter 2015/2016 in California, USA (Quan et al. 2018), or extreme rainfall in September 2016 in southeastern Australia (Hope et al. 2018). Based on the experience gained in such studies, Philip et al. (2020) presented a protocol to guide EEA studies in producing a robust statement on the anthropogenic climate change impact on specific weather events. This study adopts the methods proposed in Philip et al. (2020) to investigate how climate change has affected the probability of occurrence and the intensity of the heavy precipitation events in Central Vietnam in October 2020.

\subsection{Event definition}

The results of an extreme event attribution depend crucially on how the event is defined (Otto et al. 2012; Harrington 2017; Jézéquel et al. 2018). It is therefore an essential step in an EEA study, and adequate definition depends on the exact research question. This study aims to identify the potential role of human-induced climate change in the torrential rains that triggered the disaster impacts. Thus, the definition aims to reflect the spatial and temporal characteristics of the event that led to massive losses and damages (which are also defined by the exposure and vulnerability of people and assets affected by the hazard; see also Section 6). 
For our analysis, we focus on precipitation as the key variable because there is more long-term observational and modelled data available for precipitation than for hydrological variables like discharge or flood level and the floods were clearly caused by high precipitation. We use a class-based definition: all events with precipitation as intense as observed or higher. To select the temporal event definition, we consider that the severity of the floods and landslides and of their impacts were exacerbated by the passage of consecutive tropical typhoons/depressions in association with different large-scale weather patterns that each can lead to heavy precipitation. Specifically, water levels observed at local river gauges show that whereas the response time from precipitation to discharge in the relatively small basins was in the order of 1-2 days, water levels did not completely recede to average values since the onset of the heavy precipitation for the rest of October 2020 (Fig. 1c). This is a strong indication that the succession of events likely hampered the local drainage of water, making the direct and indirect consequences of the floods more severe. Therefore, we do not constrain the event on a particular season or type of process, but use the annual maximum of 15-day running mean of daily precipitation to define the temporal scale of the event. We call the highest value of 15-day averaged precipitation of the year henceforth Rx15day. Spatially, we focus on Central Vietnam, including the North Central and the South Central and excluding the Central Highland (Fig. 1a), where the damages were most significant, and define the maximum of Rx15day over this area as the extreme event. Note that climatologically, Rx15day has much higher values in Central Vietnam than in northern or southern Vietnam, so most high Rx15day events are in this region. As the first two high-precipitation events were closer together, we also replicate the analyses and comment briefly on the maximum of 7-day averaged precipitation, Rx7day, and the same for 3-day averaged precipitation, Rx3day.
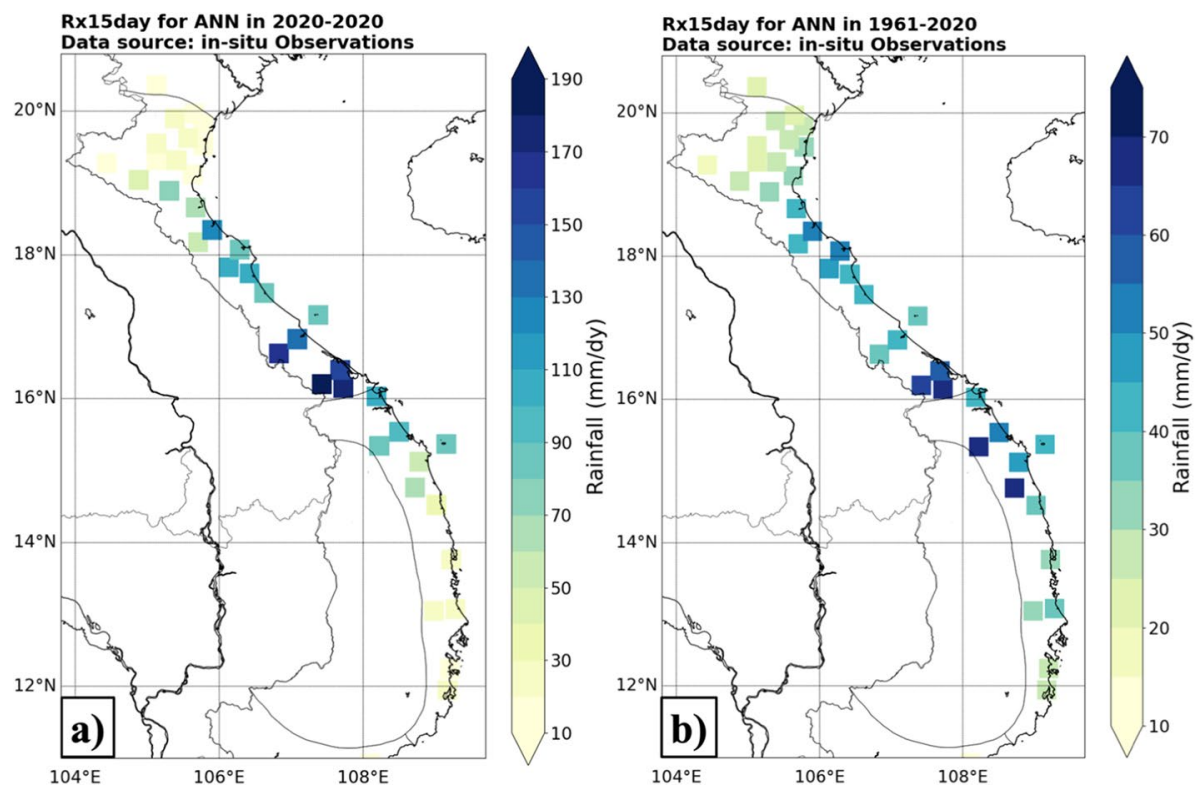

Fig. 3 Maximum observed Rx15day: a for 2020 (January to October) and b climatological mean for the whole period. Note the different colour scales of (a) and (b). 
This event definition is used in our statistical trend analysis based on observations and for the comparison of probability of the event in a world with and without greenhouse gases in two ensembles of climate model simulations. The value of Rx15day at each station is depicted in Fig. 3a and b, for year 2020 and for the average of the whole time series, respectively. The detailed steps to prepare a time series to represent a region for each dataset (i.e. observations and simulations) are presented below:

- We calculate Rx15day for every station and each model grid point that is located in North Central and South Central Vietnam (see Fig. 1a).

- We take the spatial annual maximum value of annual Rx15day among all stations (for observations) and grid points (for simulations) to obtain a time series of Rx15day of the whole region of Central Vietnam. For observations, this requires time series of all stations to overlap, which leads to a joint dataset of shorter periods if we consider more stations. For model simulations, we take into account only grid points within the boundaries of Central Vietnam to avoid considering extreme events occurring in different areas that could be influenced by different weather patterns.

\section{Data and methods}

In this section, we describe in situ observations and model simulations for precipitation and surface temperature. Observed precipitation is used in trend analyses and as a benchmark in the model evaluation. The observational-based analyses aim to determine how rare the 2020 event was in climatological context and to detect changes in the probability/intensity of this event against global mean temperature change. The model-based analyses, which makes use of large ensembles and long time series, enable the uncertainty in the attribution question to be addressed and quantified. Detailed explanations for each conceptual step can be found in Philip et al. (2020).

\subsection{Observational data}

We use daily precipitation time series provided by the Vietnam Institute of Meteorology Hydrology and Climate Change. This dataset covers 40 stations in North Central and South Central Vietnam (see Figs. 1a and 3 for station locations). The start years of observations are different among stations and range between 1961 and 1980.

To detect climate change signals in the trend of observed events, we fit a generalised extreme value (GEV) distribution that scales with a covariate related to climate change (see Section 2.3). For this, we use as a proxy of global warming the low-pass filtered (4-year moving average) global mean surface temperature (GMST), from the National Aeronautics and Space Administration/Goddard Institute for Space Science surface temperature analysis (Hansen et al. 2010; Lenssen et al. 2019). This GMST data is also used in the analysis of the PRIMAVERA simulations.

\subsection{Model and experiment descriptions}

In this study, we analyse two different sets of simulations to investigate the extreme precipitation event. One set of simulations are from the CORDEX-CORE ensemble that covers the East Asia domain (EAS-22, Teichmann et al. 2021; Torres-Alavez et al. 2021a, 
b). This dataset simulates the climate for the period of 1970-2020 using two regional climate models including RegCM4-4 and REMO2015 with horizontal resolution of 0.22 degrees. Each regional model was driven by three different CMIP5 global climate models, HadGEM2-ES, MPI-ESM, and NorESM1-M, yielding 6 simulations in total. The historical run of each simulation ends in 2005; therefore, we use the RCP8.5 scenario run for the period 2006-2020. We note that the experiment with RegCM4-4 forced by MPI-ESM starts in 1980 and is thus 10 years shorter than others. The other set of simulations is from the PRIMAVERA ensemble, which is a new generation of high-resolution global climate simulations under the High-Resolution Model Intercomparison Project (HighResMIP v1.0, Haarsma et al. 2016). We collect six global climate models that were forced by the $1 / 4^{\circ}$ sea surface temperature and sea-ice forcing from the HadISST2 dataset (Haarsma et al. 2016). These models are EC-Earth3P-HR (Haarsma et al. 2020), MPI-ESM1-2-XR (Müller et al. 2018), HadGEM3-GC31-HR (Roberts et al. 2019), CMCC-CM2-VHR4 (Cherchi et al. 2019), CNRM-CM6-1-HR (Voldoire et al. 2019), and ECMWF-IFS-HR (Roberts et al. 2018). They simulate the global climate for the period 1950-2014 with different horizontal resolutions and quantity of ensemble members. The detail of all simulations from those two ensembles is given in Table 1.

In addition to those simulations described above, we use surface temperature from the three CMIP5 global models that forced regional models REMO2015 and RegCM4-4 to compute GMST for fitting procedures for those regional climate simulations.

\subsection{Statistical methods}

In order to estimate the probability of this type of event, we use extreme value statistics. This theory suggests that the distribution of block maxima of finite size, such as our series of annual and spatial maximum values, may be approximated by a GEV distribution. We describe the effects of global warming by making the position parameter $\mu$ and scale parameter $\sigma$ as functions of a covariate assuming that $\sigma / \mu$ remains constant. As covariate, we take the 4-year smoothed GMST. The GEV function and the formula to scale GEV to different climates are given below:

$$
\begin{aligned}
& F(x)=\exp \left[-\left(1+\xi \frac{x-\mu}{\sigma}\right)^{1 / \xi}\right] \\
& \mu=\mu_{0} \exp \left(\frac{\alpha T^{\prime}}{\mu_{0}}\right) \\
& \sigma=\sigma_{0} \exp \left(\frac{\alpha T^{\prime}}{\mu_{0}}\right)
\end{aligned}
$$

In these equations, $x$ is $\mathrm{Rx} 15$ day; $\mu_{0}$ and $\sigma_{0}$ are the location, scale, and shape parameters for covariate $T^{\prime}=0 ; \alpha$ is the trend parameters; and $T^{\prime}$ is the GMST. Those constant parameters are estimated by maximum likelihood estimation. We can then specify the GMST to obtain a distribution of Rx15day for a specific climate, specifically the current climate with GMST of 2020 and an early-industrial climate with a $1.2{ }^{\circ} \mathrm{C}$ lower GMST compared to 2020. The $95 \%$ confidence interval is estimated by a nonparametric bootstrap.

We use two indices to investigate the change in statistical properties of the event between these two climates. The first index is a probability ratio (PR) estimated by taking the ratio between the exceedance probability of the event under the current climate $\left(\mathrm{P}_{1}\right)$ and the early-industrial climate $\left(\mathrm{P}_{0}\right): \mathrm{PR}=\mathrm{P}_{1} / \mathrm{P}_{0}$. The second index is the percentage change in intensity $(\Delta \mathrm{I})$ of an event with the same return period under the two climates: 


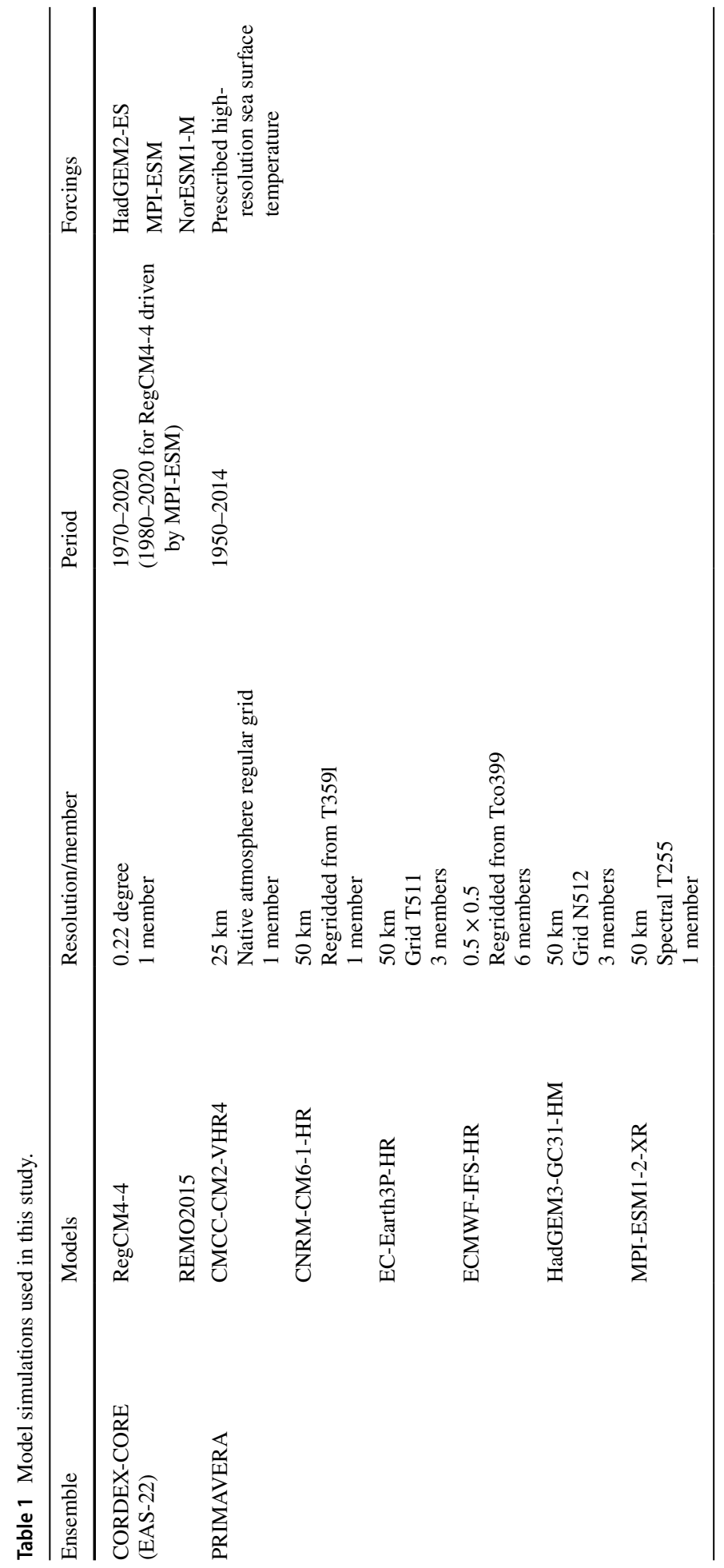




$$
\Delta I=\frac{R_{1}-R_{0}}{R_{0}} * 100
$$

with $R_{0}$ and $R_{1}$ denoting the intensity of the event in early-industrial and current climates, respectively. As the event definition has not been optimised to give a large return period, we include the year 2020 in the fits.

\section{Observational analysis: return time and trend}

In this section, we apply the GEV scale fit to 2 different periods for the observations dataset. The first period covers the full length of available data, 1961-2020. This period requires at least 58 years of data available from stations to be chosen. This condition provides 19 stations satisfied (red dots in Fig. 4c). The second period covers a span of 1975-2020 with a condition of having at least 44 years of data available for stations. Thirty-three stations satisfy this condition and hence are selected (all dots in Fig. 4c).
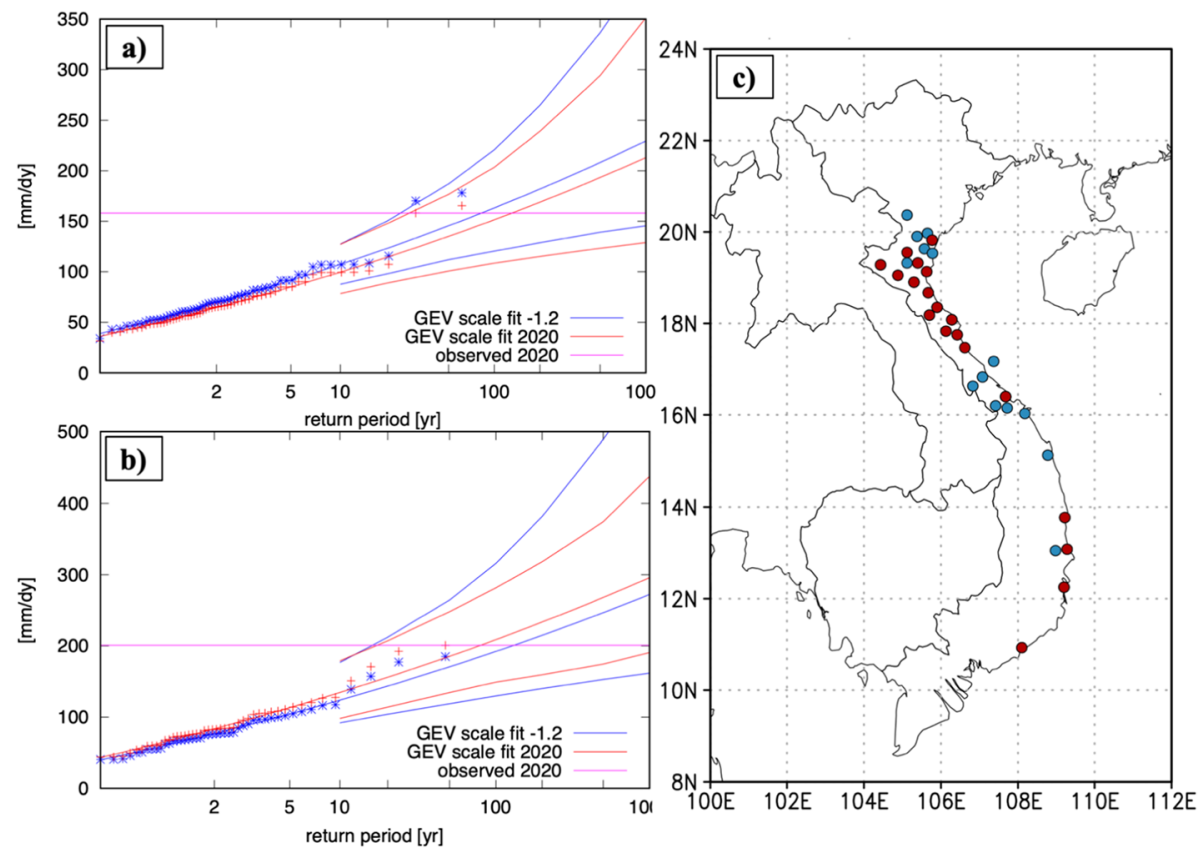

Fig. 4 Covariate-dependent generalised extreme value (GEV) distribution fit to regional maxima of Rx15day (see section "Event Definition"). a Return values of Rx15day as a function of the return period from GEV fitting to the period of 1961-2020 using stations with at least 58 years of data available. b Similar to a but for the period of 1975-2020 using stations with at least 44 years of data available. Red lines show GEV fit under the current climate (with 95\% confidence interval), and blue lines show GEV fit under the early-industrial climate; red (blue) points are data points scaled with trend from GEV fit to the current (early-industrial) climate. c Location of 19 stations (red dots) with at least 58 years available and 33 stations (red and blue dots) with at least 44 years available. 


\subsection{Analysis of point station data}

We first select the 19 stations with at least 58 years of data available. For them, we calculate regional block maxima and then perform the GEV scale fit for the period of 1961-2020 (Fig. 4a). We find that this definition produces the maximum value of 158 $\mathrm{mm} /$ day (at the Hue station) for the 2020 event. This event has a return period of 130 years (at least 32) in the current climate and could have been 1.7 times more frequent in an early-industrial climate (probability ratio of 0.6 , with confidence interval of 0.1 to 11 ). This corresponds to an intensity change of $-7 \%$ ( -33 to $35 \%$ ) compared to the early-industrial climate for an event with a return period of 130 years. These changes are not significant.

We performed the same analysis on the larger set of 33 stations that have data for the shorter period of 1975-2020 (Fig. 4b). The station (Aluoi) with the highest precipitation value for the 2020 event recorded a magnitude of $201 \mathrm{~mm} /$ day, with a return period of 80 years (with confidence interval of 17 to 3000) under the current climate. This return period corresponds to a ratio of $1.6(0.1$ to 400$)$ in probability of occurrence and $9 \%(-41$ to $86 \%)$ change in intensity. As for the analysis with the longer time period, these results are not statistically significant.

We note that in the wettest area of Central Vietnam (around $16^{\circ} \mathrm{N}$; see Fig. $3 \mathrm{~b}$ ), only the Hue station met the requirement of data length while using only the 19 stations with data from 1961 to 2020 . This means that we may miss many extreme precipitation values by this selection. This choice of period may therefore not reflect well the characteristics of the event of Central Vietnam. Therefore, we choose the period of 1975-2020 for comparison with model simulations in the attribution analysis in the next section. The 2020 event is then defined as a 1-in-80-year event of Rx15day in the current climate.

\section{Model evaluation}

In this section, we evaluate model performance in reproducing key statistical features of the observed Rx15day event and of local precipitation: its magnitude; the parameters of the fit to the GEV distribution; the spatial distribution for the whole period; and the annual cycle of precipitation. This enables selecting the appropriate models for the attribution analysis.

\subsection{Fit parameters}

We perform the GEV scale fit for all 12 models separately. For those models having more than one ensemble member, we pool all members together and then fit the GEV distribution to the pooled dataset. From the analysis in Section 3.1, the 2020 event of Rx15day has a return period of 80 years, with a magnitude of $201 \mathrm{~mm} / \mathrm{day}$ under the current climate (Fig. 4b). As part of the model validation, we estimate the magnitude of an event with a return period of 80 years in the GEV fit to simulations. The results show that the CORDEX-CORE simulations generally agree better with observations than the PRIMAVERA simulations (Table 2). However, most simulations underestimate the magnitude of Rx15day at the given return period of 80 years, except the RegCM4-4 


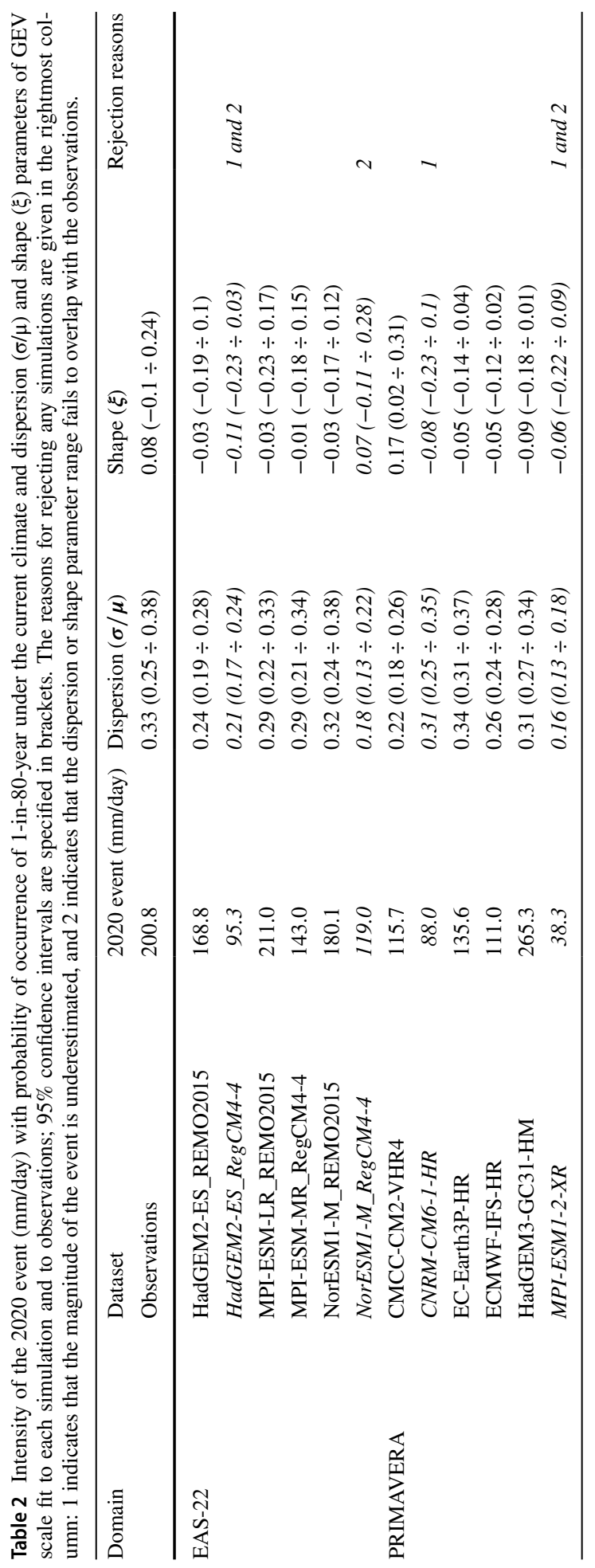


driven by MPI-ESM-MR (5\% overestimated) and the HadGEM3-GC31-HM (32\% overestimated). Markedly, a few simulations reproduce an exceedingly low magnitude of the event, for example the MPI-ESM1-2-XR (81\% lower), the CNRM-CM6-1-HR (56\% lower), and the RegCM4-4 driven by HadGEM2-ES (53\% lower).

We then compare the dispersion $(\sigma / \mu)$ and shape $(\xi)$ parameters of GEV scale fit to simulations against the fit to observations (Table 2). The purpose of this step is to eliminate the simulations that are not able to reproduce the observed distribution. The results show that all simulations yield shape parameters close to observations. However, a few models show deviations in terms of dispersion parameter. Specifically, the RegCM4-4 driven by HadGEM2-ES and by NorESM1-M and the MPI-ESM1-2-XR produce values of the dispersion parameters that are too low, with their $95 \%$ confidence intervals failing to overlap with the confidence interval of the observations.

In summary, we therefore eliminated the RegCM4-4 driven by HadGEM2-ES and NorESM1-M simulations from the CORDEX-CORE, the CNRM-CM6-1-HR, and the MPI-ESM1-2-XR simulations from PRIMAVERA from the rest of the analysis. The reasons are summarised in Table 2.

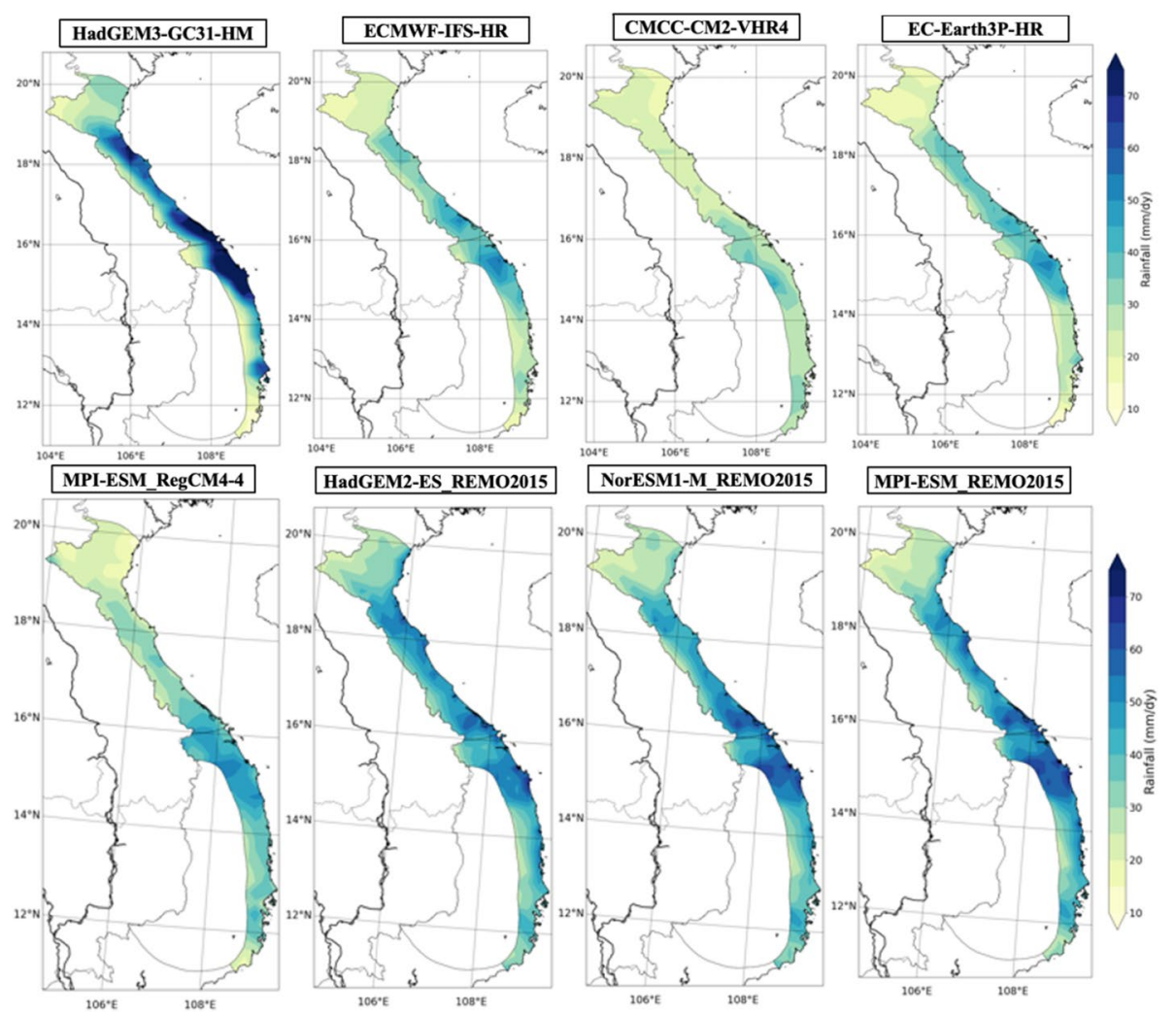

Fig. 5 Mean of Rx15day over the period of 1950-2014 from PRIMAVERA simulations (upper panels) and over the period of 1970-2020 from CORDEX-CORE simulations (lower panels). 


\subsection{Spatial pattern}

In this section, we evaluate model capability to reproduce the observed spatial distribution of Rx15day over Central Vietnam. We only show results for the 8 simulations that pass the previous assessment (Fig. 5). The observations show that the average of Rx15day over the whole period is larger from $13^{\circ} \mathrm{N}$ to $18.5^{\circ} \mathrm{N}$ than for the rest of the region, with the most extreme values between $14.5^{\circ} \mathrm{N}$ and $16.5^{\circ} \mathrm{N}$, with a peak of 70 $\mathrm{mm}$ /day (Fig. 3b). All simulations are able to reproduce this spatial feature of Rx15day, except the CMCC-CM2-VHR4 from the PRIMAVERA ensemble. However, magnitudes are substantially different across models. The three simulations with REMO2015 from the CORDEX-CORE ensemble show good agreement with observations. The bias of peak values from those simulations is trivial (around -3\%). The ECMWF-IFS-HR and EC-Earth3P-HR from PRIMAVERA and the RegCM4-4 driven by MPI-ESM from EAS-22 underestimate the peak of Rx15day by around 23\%. In contrast, the results from the HadGEM3-GC31-HM ensemble overestimate the peak of Rx15day by around $60 \%$. Because of its failure to reproduce the spatial feature of the event, CMCC-CM2-VHR4 is eliminated from the next analyses of this study.

In order to verify the ability of models to properly simulate seasonal rainfall, we additionally compute the annual cycle of rainfall averaged across all 40 stations for observations and all grid points for models over Central Vietnam for 7 models that pass the previous evaluation (figure not shown here). We find that those simulations are able to reproduce the observed peak of the rainy season for Central Vietnam in the autumn, coinciding with the active season of typhoons and tropical depressions. However, they underestimate the monthly intensity during these peak months (from -45 to $-18 \%$ from the CORDEX and from -56 to $5 \%$ from the PRIMAVERA). This suggests that these models are able to simulate the key mechanisms leading to seasonal precipitation over this area.

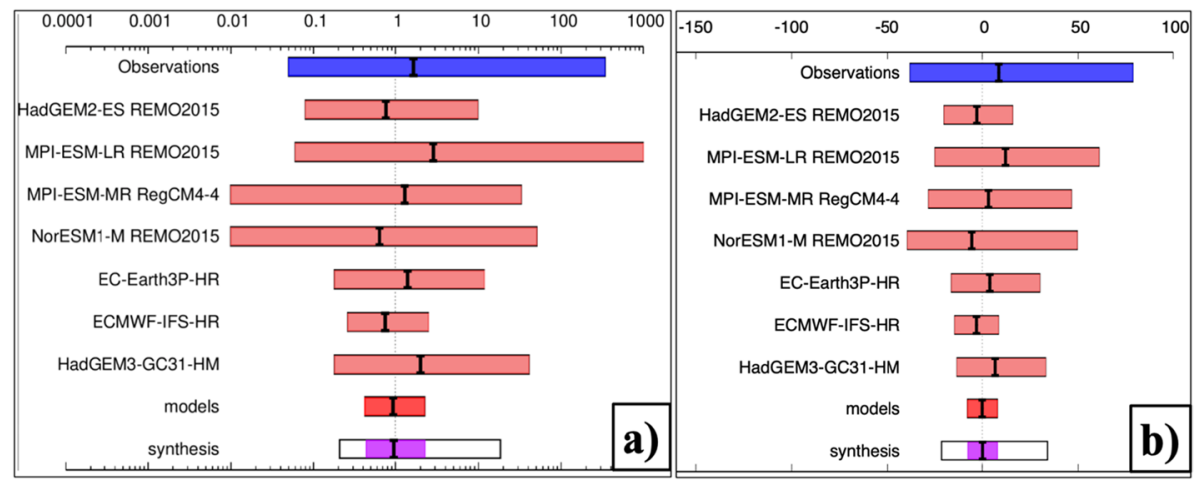

Fig. 6 Probability ratio (a): ratio between the exceedance probability of events with the magnitude of the 2020 event under current and under early-industrial climates. Intensity change (b) of events with the return period of the 2020 event between the two climates. Black vertical lines are central estimates, and coloured bars denote the $95 \%$ confidence intervals. The blue bar shows observations, the red bars show individual models, the bright red bar shows the inter-model weighted average, and the purple bar shows the overall combination of observations and models. 


\section{Multi-model attribution}

We select the GEV scale fit from 7 simulations that passed our evaluation to investigate how climate change alters the probability and intensity of the 2020 event between the current and early-industrial climates (the latter extrapolated from the beginning of the simulations). The probability ratio and the intensity change are shown in Fig. 6 . We show that the best fits from all simulations are compatible; i.e. the model spread is minor $\left(\chi^{2} / \mathrm{dof}\right.$ $\approx 0.2$ ). Their $95 \%$ confidence intervals indicate no significant change. The PRIMAVERA simulations show smaller uncertainty ranges compared to those from the CORDEX-CORE simulations. This can be explained by the effect of the larger number of ensemble members of each PRIMAVERA model.

To investigate an overall change in probability and intensity of the 2020 event, we calculate the weighted average across models with weights defined by the inverse standard error of $\log (\mathrm{PR})$ squared that gives the smallest uncertainty on the sum. The model result shows that events at least as intense as the 2020 event occur slightly less frequently in the current climate with a probability ratio of 0.9 (0.4 to 2.3) (bright red bar in Fig. 6a). This corresponds to $0 \%$ change in intensity $(-8$ to $+8 \%)$ of an event with the same return period since the early-industrial climate (Fig. 6b). These results are compatible with those from the observational-based analysis using the period of 1975-2020. Combining results from models and observations, we conclude that human-induced climate change does not seem to have changed the probability and the intensity of the 2020 event. Its probability ratio is 1.0 ( 0.4 to 2.3 ), and intensity change is $0 \%$ ( -8 to $+8 \%$, purple bars in Fig. 6).

To investigate how robust these results are for the time averaging period, here 15 days, we repeated the analysis for the annual maximum of 7-day and 3-day averaged rainfall and the same spatial definition. These time intervals gave lower return periods (50 years for Rx7day and 6 years for Rx3day) for 2020 but the same trend results: no discernible trend in probability ratio or intensity.

The impact of anthropogenic climate change on extreme precipitation events in connection with cyclonic systems has been investigated in a few studies (Emanuel 2017; Risser and Wehner 2017; van der Wiel et al. 2017; Van Oldenborgh et al. 2017; Patricola and Wehner 2018; Wang et al. 2018). They generally found that climate change increased the likelihood of occurrence and intensity of extreme rainfall during the course of a cyclone, which is not the case in this study. We find here that the climate change signal in the event is smaller than the weather noise. To contextualise this comparison, note that, unlike the above mentioned studies, our study focuses on the persistent extreme rainfall following a series of tropical cyclone circulations, especially in association with cold surges and steep mountainous regions.

\section{Vulnerability and exposure}

Our analysis of the hazard event that triggered the flood disasters in Central Vietnam in October 2020 demonstrates that there is no clear indication that climate change is affecting the risk of this particular flood event. However, the risk is determined by a combination of hazard, exposure, and vulnerability (Cardona et al. 2012; Kundzewicz et al. 2019). The very reason we undertook this study, and our spatial and temporal event definition, was informed by the combination of these three factors which together determine the 
scale of human and economic losses (see Section 1). Similarly, in interpreting the results of our analysis of changes in hazards to inform risk management, it is important to consider trends in the risk factors. In particular, population growth, socio-economic development, urbanisation, and pressures on natural resources have increased Vietnam's disaster risk. A 2016 World Bank study estimated that 33\% of Vietnam's population is exposed to the risk of a 1-in-25-year flood event (albeit primarily for coastal flooding). Therefore, a 1-in-80-year event such as the one analysed here would indeed be expected to affect large numbers of people. Although in absolute terms exposure is concentrated in Hanoi and HoChi-Minh City rather than in Central Vietnam, secondary cities in Central Vietnam have some of the country's highest urban growth rates (Rentschler et al. 2020). The more recent elevation dataset, CoastalDEM, implies that at present 28 million Vietnamese citizens are exposed to coastal floods of 1-year return period, and that with the sea level changes expected up to 2100 (Tran et al. (2016), and keeping all else equal), this number would be 31-37 million (Kulp and Strauss 2019). Based on its high exposure to floods and storms, with major economic activity also concentrated in low-lying areas, the World Bank has listed Vietnam as among the countries worst affected by climate change (ADB 2020). Vietnam has made progress in reducing disaster risk, through the implementation of effective early warning systems, the adoption of a multi-layered disaster risk governance structure, the many realisations of measures for flood risk protection, and vulnerability reduction (UNDRR 2020). For a review of the scientific inputs to flood risk management in Vietnam, see Nguyen et al. (2021). Nevertheless, risk information is fragmented and incomplete, not sufficiently adopted in planning nor enforced in standards (Rentschler et al. 2020; Nguyen et al. 2021), as implied by the delay in the implementation of flood protection measures in highly exposed Ho Chi Minh City (Scussolini et al. 2017; Vachaud et al. 2019). Even relatively frequent (and thus less intense), flood events have a high impact on extreme poverty (ADB (2017); based on analysis in Greater Mekong Subregion). It should be noted that this vulnerability needs to be assessed in relation not only to the intensity of the precipitation and the resultant flood event, but also the duration thereof (Ward et al. 2016), an aspect that is often neglected in flood risk assessments. Also, as suggested in the hydrographs of discharge of local rivers in the areas affected in October 2020 (Fig. 1c), flood waters do not seem to have receded during much of the month, likely causing widespread so-called nuisance flooding (Moftakhari et al. 2017). The consequences of the repetitive large floods interspersed with prolonged nuisance flooding in Central Vietnam during October 2020 are akin to consecutive disasters, which can create highly non-linear compound socio-economic consequences (de Ruiter et al. 2020). In this context, it should also be noted that subsequent disaster events, including those related to typhoons Goni, Etau, and Vamco (not included in this study), further aggravated the challenges in central Vietnam. Quantification of these effects of consecutive disasters is in its early stages and needs to be carefully considered in the context of hazard attribution studies.

\section{Summary and conclusions}

The disastrous flooding resulting from persistent heavy precipitation occurring over Central Vietnam in October 2020 was associated with five sequential tropical cyclones including two depressions and three typhoons. The floods and landslides caused more than 200 deaths, more than 500 people injured, and damage totalled approximately 1.2 billion US dollars. We use in situ observations to detect climate change signals for the 
spatial maximum of extreme 15-day rainfall (Rx15day) over Central Vietnam using a generalised extreme value (GEV) distribution that scales with smoothed global mean surface temperature. The result shows that the event in October 2020 over Central Vietnam has a return period of 80 (lower bound of 17) years. The fit to the observations however does not show a significant change in the probability of the event. Although the best fit value makes it more likely by a factor of 1.6, the confidence interval has a lower bound of 0.1 , abundantly encompassing 1.0 (no change). Similarly, the change in intensity is between -41 and $86 \%$, which does not give much useful information. The very large uncertainty bounds are due to the relatively short length of the time series (46 years) and a large event in spatial scale that precludes stations pooling of observations to increase the sample size.

We use two model ensembles including 6 PRIMAVERA and 6 CORDEX-CORE models to perform the attribution part. Four models from CORDEX-CORE and 3 from PRIMAVERA reasonably reproduce the event, showing good agreement with observations in terms of spatial distribution of Rx15day, annual cycle, and reproduction of characteristics of GEV distribution to those simulations.

We perform the similar GEV scale fit to each model to investigate the trend from those simulations. On average, model results produce no change, with a ratio of 0.9 (0.4 to 2.3) between the probability of occurrence with and without anthropogenic global warming, and with $0 \%$ ( -8 to $8 \%$ ) change in the intensity of an event with the probability of the 2020 event. Combining model results with observations produces a probability ratio of 1.0 ( 0.4 to 2.3 ) and the same intensity change as from models average. The synthesis analysis therefore also shows no influence of global warming on the highest 15-day averaged precipitation of the year in Central Vietnam. It should be noted that the uncertainties are still fairly large, and an increase with Clausius-Clapeyron scaling ratio that is often seen for shorter duration extremes is not excluded when scaling with the average sea surface temperature in front of the coast defined by $15^{\circ} \mathrm{N}$ to $17^{\circ} \mathrm{N}$ and $106^{\circ} \mathrm{E}$ to $120^{\circ} \mathrm{E}$ (about $0.8^{\circ} \mathrm{C}$ since early-industrial, giving a theoretical scaling of $6 \%$, which has a probability of about $7 \%$ in the confidence interval). Similar analyses of 7-day and 3-day averaged precipitation, roughly corresponding to two or one precipitation events due to tropical cyclones, give very similar results.

These null results are also a reflection of the fact that in relation to these precipitation extremes, changes due to global warming are much smaller than natural variability in weather. However, while we found no significant climate change-related trend in risk in this event, we emphasise that disaster risk reduction remains an urgent priority given the high vulnerability and exposure of the affected region (and in addition, we note that other climate-related changes in hazards, including sea level rise, do affect the risks facing Vietnam). Moreover, as both observations and model simulations will be extended with the passage of time, we encourage more climate change impact investigations on the extreme in the future that help adaptation and mitigation plans and raise awareness in the country.

Availability of data and material All data used in this study are available via the Climate Explorer at https:// climexp.knmi.nl. All simulations can also be found on ESGF nodes.

Code availability Not applicable

\section{Declarations}

Conflict of interest The authors declare no competing interests. 
Open Access This article is licensed under a Creative Commons Attribution 4.0 International License, which permits use, sharing, adaptation, distribution and reproduction in any medium or format, as long as you give appropriate credit to the original author(s) and the source, provide a link to the Creative Commons licence, and indicate if changes were made. The images or other third party material in this article are included in the article's Creative Commons licence, unless indicated otherwise in a credit line to the material. If material is not included in the article's Creative Commons licence and your intended use is not permitted by statutory regulation or exceeds the permitted use, you will need to obtain permission directly from the copyright holder. To view a copy of this licence, visit http://creativecommons.org/licenses/by/4.0/.

\section{References}

ADB (2020) https://www.adb.org/sites/default/files/publication/653596/climate-risk-country-profile-vietnam.pdf

ADB (2017) http://dx.doi.org/10.22617/TCS178804-2

Brown K (2009) https://www.adb.org/sites/default/files/project-document/65077/40621-vie-tacr.pdf

Cardona O-D, van Aalst MK, Birkmann J, et al. (2012) Determinants of risk: Exposure and vulnerability. In Managing the Risks of Extreme Events and Disasters to Advance Climate Change Adaptation: Special Report of the Intergovernmental Panel on Climate Change (Vol. 9781107025066, pp. 65-108). Cambridge University Press. https://doi.org/10.1017/CBO9781139177245.005

Chen T-C, Tsay J-D, Yen M-C, Matsumoto J (n.d.) Interannual Variation of the Late Fall Rainfall in Central Vietnam. J Clim 25:392-413 https://doi.org/10.1175/JCLI-D-11-00068.1

Chen T-C, Yen M-C, Tsay J-D et al (2012) Forecast advisory for the late fall heavy rainfall/flood event in Central Vietnam developed from diagnostic analysis. Weather Forecast 27:1155-1177. https://doi.org/ 10.1175/WAF-D-11-00104.1

Cherchi A, Fogli PG, Lovato T, et al (2019) Global mean climate and main patterns of variability in the CMCC-CM2 coupled model. J Adv Model Earth Syst 11:185-209. https://doi.org/10.1029/2018M S001369

de Ruiter MC, Couasnon A, van den Homberg MJC, et al. (2020) Why we can no longer ignore consecutive disasters. Earths Futur 8:e2019EF001425 https://doi.org/10.1029/2019EF001425

Eden JM, Wolter K, Otto FEL, van Oldenborgh GJ (2016) Multi-method attribution analysis of extreme precipitation in Boulder, Colorado. Environ Res Lett 11:124009

Emanuel K (2017) Assessing the present and future probability of Hurricane Harvey\{ \textquoteright $\}$ s rainfall. Proc Natl Acad Sci 114:12681-12684. https://doi.org/10.1073/pnas.1716222114

Gobin A, Nguyen HT, Pham VQ, Pham HTT (2016) Heavy rainfall patterns in Vietnam and their relation with ENSO cycles. Int J Climatol 36:1686-1699. https://doi.org/10.1002/joc.4451

Haarsma R, Acosta M, Bakhshi R et al (2020) HighResMIP versions of EC-Earth: EC-Earth3P and ECEarth3P-HR - description, model computational hack\{ \break $\}$ performance and basic validation. Geosci Model Dev 13:3507-3527. https://doi.org/10.5194/gmd-13-3507-2020

Haarsma RJ, Roberts MJ, Vidale PL et al (2016) High resolution model intercomparison project (HighResMIP v1.0) for CMIP6. Geosci Model Dev 9:4185-4208. https://doi.org/10.5194/ gmd-9-4185-2016

Hansen J, Ruedy R, Sato M, Lo K (2010) Global surface temperature change. Rev Geophys 48 https://doi. org/10.1029/2010RG000345

Harrington LJ (2017) Investigating differences between event-as-class and probability density-based attribution statements with emerging climate change. Clim Change 141:641-654. https://doi.org/10.1007/ s10584-017-1906-3

Hersbach H, Bell B, Berrisford P et al (2020) The ERA5 global reanalysis. Q J R Meteorol Soc 146:1999_ 2049. https://doi.org/10.1002/qj.3803

Hope P, Lim E-P, Hendon H, Wang G (2018) The effect of increasing CO2 on the extreme September 2016 rainfall across Southeastern Australia. Bull Am Meteorol Soc 99:S133-S138. https://doi.org/10.1175/ bams-d-17-0094.1

Jézéquel A, Dépoues V, Guillemot $\mathrm{H}$ et al (2018) Behind the veil of extreme event attribution. Clim Change 149:367-383. https://doi.org/10.1007/s10584-018-2252-9

Kulp SA, Strauss BH (2019) New elevation data triple estimates of global vulnerability to sea-level rise and coastal flooding. Nat Commun 10:1-12

Kundzewicz ZW, Su B, Wang Y et al (2019) Flood risk in a range of spatial perspectives - from global to local scales. Nat Hazards Earth Syst Sci 19:1319-1328. https://doi.org/10.5194/nhess-19-1319-2019 
Lawal KA, Abatan AA, Angélil O et al (2016) The late onset of the 2015 Wet Season in Nigeria. Bull Am Meteorol Soc 97:S63-S69. https://doi.org/10.1175/BAMS-D-16-0131.1

Lenssen NJL, Schmidt GA, Hansen JE et al (2019) Improvements in the GISTEMP uncertainty model. J Geophys Res Atmos 124:6307-6326. https://doi.org/10.1029/2018JD029522

Moftakhari HR, AghaKouchak A, Sanders BF, Matthew RA (2017) Cumulative hazard: the case of nuisance flooding. Earths Futur 5:214-223. https://doi.org/10.1002/2016EF000494

Müller WA, Jungclaus JH, Mauritsen T et al (2018) A higher-resolution version of the Max Planck Institute Earth System Model (MPI-ESM1.2-HR). J Adv Model Earth Syst 10:1383-1413. https://doi.org/10. $1029 / 2017$ MS001217

NCHMF (2000) is a report in Vietnamese issued by the National Centre for Hydro-Meteorological Forecasting, Hanoi, Vietnam

Nguyen DN, Nguyen TH (2004) Climate and climatic resources of Vietnam. Agricultural Publisher, Hanoi

Nguyen MT, Sebesvari Z, Souvignet M, et al. (2021) Understanding and assessing flood risk in Vietnam: current status, persisting gaps, and future directions. J Flood Risk Manag e12689 https://doi.org/10. 1111/jfr3.12689

Otto FEL, Massey N, Van Oldenborgh GJ, et al. (2012) Reconciling two approaches to attribution of the 2010 Russian heat wave, Geophys. Res Lett 39:L04702. https://doi.org/10.1029/2011GL050422.

Patricola CM, Wehner MF (2018) Anthropogenic influences on major tropical cyclone events. Nature 563:339-346. https://doi.org/10.1038/s41586-018-0673-2

Pham NTT, Nguyen QH, Ngo AD et al (2018) Investigating the impacts of typhoon-induced floods on the agriculture in the central region of Vietnam by using hydrological models and satellite data. Nat Hazards 92:189-204. https://doi.org/10.1007/s11069-018-3202-6

Philip S, Kew S, van Oldenborgh GJ et al (2020) A protocol for probabilistic extreme event attribution analyses. Adv Stat Climatol Meteorol Oceanogr 6:177-203. https://doi.org/10.5194/ascmo-6-177-2020

Philip S, Kew SF, van Oldenborgh GJ et al (2017) Validation of a rapid attribution of the May/June 2016 flood-inducing precipitation in France to climate change. J Hydrometeorol 19:1881-1898. https://doi. org/10.1175/JHM-D-18-0074.1

Quan X-W, Hoerling M, Smith L et al (2018) Extreme California rains during winter 2015/16: a change in El Niño teleconnection? Bull Am Meteorol Soc 99:S49-S53. https://doi.org/10.1175/BAMS-D-17-0118.1

Rentschler J, Robbé S de V, Braese J et al (2020) Resilient shores: Vietnam's coastal development-between opportunity and disaster risk. World Bank, Washington DC

Risser MD, Wehner MF (2017) Attributable human-induced changes in the likelihood and magnitude of the observed extreme precipitation during hurricane Harvey. Geophys Res Lett 44:12,412-457,464. https:// doi.org/10.1002/2017GL075888

Roberts CD, Senan R, Molteni F et al (2018) Climate model configurations of the ECMWF Integrated Forecasting System (ECMWF-IFS cycle 43r1) for HighResMIP. Geosci Model Dev 11:3681-3712. https:// doi.org/10.5194/gmd-11-3681-2018

Roberts MJ, Baker A, Blockley EW et al (2019) Description of the resolution hierarchy of the global coupled HadGEM3-GC3.1 model as used in CMIP6 HighResMIP experiments. Geosci Model Dev 12:4999-5028. https://doi.org/10.5194/gmd-12-4999-2019

Scussolini P, Tran TVT, Koks E et al (2017) Adaptation to sea level rise: a multidisciplinary analysis for Ho Chi Minh City, Vietnam. Water Resour Res 53:10841-10857. https://doi.org/10.1002/2017WR021344

Supari Tangang F, Juneng L et al (2020) Multi-model projections of precipitation extremes in Southeast Asia based on CORDEX-Southeast Asia simulations. Environ Res 184:109350. https://doi.org/10. 1016/j.envres.2020.109350

Takagi H (2019) Statistics on typhoon landfalls in Vietnam: can recent increases in economic damage be attributed to storm trends? Urban Clim 30:100506. https://doi.org/10.1016/j.uclim.2019.100506

Teichmann C, Jacob D, Remedio AR, et al. (2021) Assessing mean climate change signals in the global CORDEXCORE ensemble. Clim Dyn 57:1269-1292. https://doi.org/10.1007/s00382-020-05494-X

Torres-Alavez JA, Das S, Corrales-Suastegui A, et al. (2021a) Torres-Alavez, J.A., Das, S., CorralesSuastegui, A. et al. Future projections in the climatology of global low-leveljets from CORDEX-CORE simulations. Clim Dyn 57:1551-1569. https://doi.org/10.1007/s00382-021-05671-6

Torres-Alavez JA, Glazer R, Giorgi F, et al. (2021b) Future projections in tropical cyclone activity over multiple CORDEX domains from RegCM4 CORDEX-CORE simulations. Clim Dyn 57:1507-1531. https://doi.org/10.1007/s00382-021-05728-6

Tran T, Nguyen VT, Huynh Thi Lan H, et al (2016) Climate change and sea level rise scenarios for Vietnam. Minist Nat Resour Environ Hanoi, Vietnam

Tuan BM (2019) Extratropical forcing of submonthly variations of rainfall in Vietnam. J Clim 32:23292348. https://doi.org/10.1175/JCLI-D-18-0453.1 
UNDRR (2020) Disaster risk reduction in Viet Nam: status report 2020. United Nations Office for Disaster Risk Reduction (UNDRR), Regional Office for Asia and the Pacific Asian Disaster Preparedness Center, Bangkok, Thailand

Vachaud G, Quertamp F, Phan TSH et al (2019) Flood-related risks in Ho Chi Minh City and ways of mitigation. J Hydrol 573:1021-1027. https://doi.org/10.1016/j.jhydrol.2018.02.044

van der Wiel K, Kapnick SB, van Oldenborgh GJ et al (2017) Rapid attribution of the August 2016 floodinducing extreme precipitation in south Louisiana to climate change. Hydrol Earth Syst Sci 21:897921. https://doi.org/10.5194/hess-21-897-2017

van Oldenborgh GJ, Otto FEL, Haustein K, AchutaRao K (2016) The heavy precipitation event of December 2015 in Chennai, India. Bull Am Meteorol Soc 97:S87-S91. https://doi.org/10.1175/ BAMS-D-16-0129.1

Van Oldenborgh GJ, Van Der Wiel K, Sebastian A et al (2017) Attribution of extreme rainfall from Hurricane Harvey, August 2017. Environ Res Lett 12:124009

Villafuerte MQ, Matsumoto J (2015) Significant influences of global mean temperature and ENSO on extreme rainfall in Southeast Asia. J Clim 28:1905-1919. https://doi.org/10.1175/JCLI-D-14-00531.1

Voldoire A, Saint-Martin D, Sénési S et al (2019) Evaluation of CMIP6 DECK Experiments With CNRMCM6-1. J Adv Model Earth Syst 11:2177-2213. https://doi.org/10.1029/2019MS001683

Van Vu T, Nguyen HT, Van Nguyen T et al (2015) Effects of ENSO on autumn rainfall in Central Vietnam. Adv Meteorol 2015:264373. https://doi.org/10.1155/2015/264373

Wang C, Liang J, Hodges KI (2017) Projections of tropical cyclones affecting Vietnam under climate change: downscaled HadGEM2-ES using PRECIS 2.1. Q J R Meteorol Soc 143:1844-1859. https:// doi.org/10.1002/qj.3046

Wang S-YS, Zhao L, Yoon J-H et al (2018) Quantitative attribution of climate effects on Hurricane Harvey's extreme rainfall in Texas. Environ Res Lett 13:54014. https://doi.org/10.1088/1748-9326/aabb85

Ward PJ, Kummu M, Lall U (2016) Flood frequencies and durations and their response to El Niño Southern Oscillation: Global analysis. J Hydrol 539:358-378. https://doi.org/10.1016/j.jhydrol.2016.05.045

Wolf A, Roberts WHG, Ersek V et al (2020) Rainwater isotopes in central Vietnam controlled by two oceanic moisture sources and rainout effects. Sci Rep 10:16482. https://doi.org/10.1038/ s41598-020-73508-Z

Wu P, Fukutomi Y, Matsumoto J (2012) The impact of intraseasonal oscillations in the tropical atmosphere on the formation of extreme Central Vietnam Precipitation. SOLA 8:57-60. https://doi.org/10.2151/ sola.2012-015

Yen M-C, Chen T-C, Hu H-L et al (2011) Interannual variation of the fall rainfall in Central Vietnam. J Meteorol Soc Japan Ser II 89A:259-270. https://doi.org/10.2151/jmsj.2011-A16

Yokoi S, Matsumoto J (2008) Collaborative effects of cold surge and tropical depression? Type disturbance on heavy rainfall in Central Vietnam. Mon Weather Rev 136:3275-3287. https://doi.org/10.1175/ 2008MWR2456.1

\section{Tribute}

We would like to express our deep gratitude and respect to Geert Jan van Oldenborgh, co-author of this manuscript, who sadly passed away on 12 October 2021. His outstanding contribution to the science of extreme event attribution and his passion to provide the knowledge, data, and analysis tools that are most relevant for society and especially for vulnerable communities has been enormous. We lost a pioneering scientist, a humble colleague, and an amazing friend.

Publisher's Note Springer Nature remains neutral with regard to jurisdictional claims in published maps and institutional affiliations. 


\section{Authors and Affiliations}

Linh N. Luu ${ }^{1,2} \cdot$ Paolo Scussolini ${ }^{1,3} \cdot$ Sarah Kew ${ }^{1} \cdot$ Sjoukje Philip ${ }^{1}$. Mugni Hadi Hariadi ${ }^{1} \cdot$ Robert Vautard $^{4} \cdot$ Khiem Van Mai $^{5}$. Thang Van $\mathrm{Vu}^{2}$. Kien Ba Truong ${ }^{2}$. Friederike Otto ${ }^{6}$. Gerard van der Schrier ${ }^{1}$. Maarten K. van Aalst ${ }^{7,8,9}$. Geert Jan van Oldenborgh ${ }^{1}$

1 Royal Netherlands Meteorological Institute (KNMI), De Bilt, Netherlands

2 Vietnam Institute of Meteorology Hydrology and Climate Change, Hanoi, Vietnam

3 Institute for Environmental Studies, Vrije Universiteit Amsterdam, Amsterdam, Netherlands

4 Laboratoire des Sciences du Climat et de l'Environnement, UMR 8212 CEA-CNRS-UVSQ, Université Paris-Saclay and IPSL, Gif-sur-Yvette, France

5 National Centre for Hydro - Meteorological Forecasting, Hanoi, Vietnam

6 Grantham Institute, Imperial College London, London, UK

7 Faculty of Geo-information Science and Earth Observation, University of Twente, Enschede, The Netherlands

8 Red Cross Red Crescent Climate Centre, The Hague, The Netherlands

9 International Research Institute for Climate and Society, Columbia University, New York, NY, USA 